\title{
Maternofetal outcome in early versus late detected asymptomatic bacteriuria of pregnancy
}

\author{
Indira Guntoory ${ }^{1}$, Poornima Penmetsa ${ }^{1 *}$, \\ Sarath B. Rayapu ${ }^{2}$, Lakshmana R. Nambaru ${ }^{3}$
}

\begin{abstract}
${ }^{1}$ Department of Obstetrics and Gynecology, ${ }^{2}$ Department of Microbiology, ${ }^{3}$ Department of Community Medicine, MIMS, Nellimerla, Vizianagaram district, Andhra Pradesh, India
\end{abstract}

Received: 13 November 2017

Accepted: 30 November 2017

\section{*Correspondence:}

Dr. Poornima Penmetsa,

E-mail: poornimaravi2006@gmail.com

Copyright: () the author(s), publisher and licensee Medip Academy. This is an open-access article distributed under the terms of the Creative Commons Attribution Non-Commercial License, which permits unrestricted non-commercial use, distribution, and reproduction in any medium, provided the original work is properly cited.

\begin{abstract}
Background: Urinary tract infection in pregnancy is a problem of global significance. Untreated asymptomatic bacteriuria in pregnancy is known to be associated with maternal and foetal outcome in the form of symptomatic urinary tract infection (UTI), acute pyelonephritis, anaemia, pregnancy induced hypertension (PIH), preterm labour (PTL), low birth weight (LBW), intrauterine growth restriction (IUGR) and prematurity. This study is aimed to compare the maternal and foetal outcome of pregnant women with bacteriuria with that of women without bacteriuria and also to see if screening later in pregnancy at 28-37 weeks of gestation is as effective as screening at less than 20 weeks of pregnancy in terms of maternofoetal outcome.

Methods: 165 pregnant women attending the antenatal clinic at MIMS, Nellimerla, Vizianagaram district, Andhra Pradesh, India were screened for asymptomatic bacteriuria by urine culture and sensitivity. They were grouped into asymptomatic bacteriuria negative and culture positive groups. Culture positives were further grouped as early detected and late detected group based on the gestational age at sampling. They were followed up till delivery. The maternofoetal outcome was compared between different groups by computing Odd's ratio and $\mathrm{P}$ value of less than 0.05 was taken as significant.

Results: There was no statistically significant increase in adverse maternofoetal outcome between early detected and bacteriuria negative group. The women of late detected group had greater odds of developing symptomatic UTI, PIH, PTL, LBW, IUGR and neonatal intensive care unit admissions when compared to early detected and bacteriuria negative group which was statistically significant.

Conclusions: Screening for asymptomatic bacteriuria early in pregnancy at less than 20 weeks is more effective in reducing the adverse maternofoetal outcome.
\end{abstract}

Keywords: Asymptomatic, Bacteriuria, Early detected, Late detected

\section{INTRODUCTION}

Urinary tract infection is a common medical complication of pregnancy. Women are more susceptible than men due to short urethra and contamination of the urogenital tract with faecal flora due to the proximity of the urogenital tract to the anal canal. Bacteriuria during pregnancy may be classified as Asymptomatic bacteriuria (ASB), infection of the lower urinary tract (cystitis) and infection of the upper urinary tract (pyelonephritis). Pregnancy in itself is a risk factor for the development of urinary tract infection due to the anatomical, physiological and immunological changes that occur in pregnancy. $90 \%$ of pregnant women develop urethral dilatation starting by about $6^{\text {th }}$ week of pregnancy, increase in bladder volume, 
decrease in the tone of urinary bladder, decrease in the peristalsis of ureter and decrease in the urethral tone resulting in urinary stasis and vesicoureteral reflux. Glycosuria and aminoaciduria in pregnancy further increase the risk. Increased alkalinisation of urine by increased excretion of bicarbonates enhance the colonization of the urinary tract by uropathogens. These changes predispose the pregnant women to urinary tract infection. Though asymptomatic bacteriuria is found in both males and females, females are disproportionately affected more than males.

Asymptomatic bacteriuria is defined as persistent bacterial colonisation of the urinary tract without urinary symptoms with a colony count of more than 1 lakh colony forming units/ml of a single organism. ${ }^{1}$ The relationship between asymptomatic bacteriuria in pregnancy with symptomatic urinary tract infections and adverse pregnancy outcomes was first suggested by Kass in $1959 .^{2}$ Women with asymptomatic bacteriuria in pregnancy are at an increased risk of developing anaemia, pregnancy induced hypertension $(\mathrm{PIH})$, preterm labour (PTL), low birth weight (LBW) babies, acute cystitis and acute pyelonephritis (APN). ${ }^{3}$ If untreated, $20-40 \%$ of women with asymptomatic bacteriuria in pregnancy tend to develop acute pyelonephritis and up to $30 \%$ develop symptomatic Cystitis. ${ }^{1}$ Acute pyelonephritis which occurs in $2 \%$ of pregnant women is associated with severe maternal and foetal morbidity and mortality such as preterm labour, septicaemia, ARDS, acute renal dysfunction. It is now considered to be an independent risk factor for preterm delivery. ${ }^{4}$ Treatment of asymptomatic bacteriuria during pregnancy reduces the risk of pyelonephritis from $20-35 \%$ to $1-4 \%$ and the risk of having a low birth weight baby from $15 \%$ to $5 \% .5,6$ Age, parity, sexual activity, lower socioeconomic status, diabetes, multiple pregnancy, sickle cell disease, urinary tract malformations are known risk factors for asymptomatic bacteriuria of pregnancy. ${ }^{7}$

The US preventive services task force recommend screening for asymptomatic bacteriuria of pregnancy with urine culture at 12-16 weeks of gestation or at their first prenatal visit, if later. ${ }^{7}$ Routine screening for asymptomatic bacteriuria of pregnancy is now the standard of care in developed countries. Studies from the west have shown the prevalence of ASB to be in the range of $2-10 \% .{ }^{8,9}$ However several studies in India have shown the prevalence of ASB to be much higher in the range of $8-21.1 \%^{10-13}$ Moreover, studies show that screening and treatment of ASB reduces the risk of pyelonephritis in a population with moderate to high prevalence of bacteriuria. ${ }^{14}$ Adam et al proposed that screening and treatment of ASB in pregnancy is the most cost effective intervention at the primary level of health care to achieve the millennium development goal for health. ${ }^{15}$ However it is not being practised in developing countries like India. The screening tests used commonly in the primary health care setting such as dipstick analysis and presence of pyuria have poor positive predictive value for detecting bacteriuria. ${ }^{7}$ Moreover a negative urine test for pyuria is not a reliable indicator of the absence of ASB in pregnant women. ${ }^{16}$ Urine culture is the gold standard for detecting ASB ${ }^{8}$ Earlier studies have shown that the prevalence of ASB was higher in the second and third trimesters. Women with no bacteriuria in their initial examination in the first trimester developed bacteriuria in the later trimesters. ${ }^{17}$ The poor rural women in our country may not have their first antenatal visit prior to 20 weeks or the facility for urine culture and sensitivity may not be available at the place of antenatal care. Some of these women may be seen late in pregnancy or may undergo urine culture late in pregnancy. So, this study was undertaken to compare the maternal and foetal outcome of ASB positive women with ASB negative women and also to compare the materno foetal outcome in early detected and treated with late detected and treated women with ASB.

\section{METHODS}

This is a prospective cohort study conducted in the Department of Obstetrics and Gynaecology, Maharajah's Institute of Medical Sciences, Nellimerla, Vizianagaram district of Andhra Pradesh, India over a two-year period from September 2015 to August 2017 after obtaining institutional ethics committee approval.

Calculation of sample size-Size of the sample was calculated by using the formula: $Z^{2} P(1-P) \div d^{2}$ where $\mathrm{Z}=1.96, \mathrm{P}$ is the prevalence of $\mathrm{ASB}, \mathrm{d}$ is the tolerance error of $5 \%$. An earlier study by the same author in this region showed the prevalence of ASB to be $11 \% .{ }^{18}$ The sample size was calculated as 165 taking prevalence rate as $11 \%$ and attrition rate of $10 \%$.

Pregnant women with a gestational age of less than 20 weeks and with a gestational age of 28-37 weeks due to late registration were screened for ASB in their first visit to the hospital. Pregnant women with ASB detected and treated at less than 20 weeks were grouped as early detected (ED) group and women with a gestational age of 28-37 weeks were grouped as late detected (LD) group. The purpose of the study was explained to the women and those who gave informed written consent and were willing to come for follow up and deliver in our hospital only were included in our study.

\section{Exclusion criteria}

- Women with symptoms of UTI such as dysuria, fever associated with chills and rigors and supra pubic pain.

- Diabetes complicating pregnancy.

- Known cases of sickle cell anemia.

- Patients with known abnormality of urinary tract.

- Previous history of preterm delivery.

- Pregnant women already diagnosed to be having hypertension or preeclampsia. 
- Women with unreliable dates and without a dating scan.

- Women who used Antibiotics in the preceding 2 weeks.

Information was collected about their age, parity, gestational age and socioeconomic status according to B G Prasad scale. ${ }^{19}$ A detailed obstetric history and relevant past history was noted through a structured questionnaire. All these women were explained about the collection of the sample and they were asked to collect a clean catch midstream sample of urine into a wide mouthed sterile container with a well fitted lid. All these samples were processed within one hour of collection using standard microbiological procedures. The samples were cultured on dried plates of Mac conkey's agar and sheep blood agar by standard loop method. They were subjected to overnight aerobic incubation at $37^{\circ} \mathrm{C}$. The plates were read after 24 hours and the organisms grown were identified by their growth characteristics. Samples which showed a bacterial count of $10^{5}$ colony forming units per $\mathrm{ml}(\mathrm{cfu} / \mathrm{ml})$ or more of a single organism were considered as significant or ASB positive or culture positive cases.

In case of Staphylococcus aureus, a count of $10^{2} \mathrm{cfu} / \mathrm{ml}$ was taken as significant. If no growth is detected, the plates were incubated for another 24 hours before a negative report is issued. Women with counts less than $10^{5} \mathrm{cfu} / \mathrm{ml}$ were considered as insignificant or ASB negative or culture negative group and were taken as controls. The sensitivity of these organisms to antibiotics which are relatively safe to be prescribed in pregnancy such as Nitrofurantoin, Ampicillin, Amoxicillin with Clavulanic acid, Cefotaxime, Ceftazidime, Cefuroxime, Amikacin and Imipenem was tested by the standard Kirby Bauer disc diffusion test of the Clinical and Laboratory Standards Institute.

All the pregnant women who were culture positive were given treatment with appropriate antibiotics for 7 days duration. A repeat culture was done after 2 weeks of completion of the treatment to confirm the clearance of bacteriuria. If any woman had persistence of bacteriuria, another course of appropriate antibiotics was given. All the women were followed up till delivery and up to 1 week postpartum.

Details of maternal morbidity such as the development of symptomatic UTI (associated with dysuria, frequency of micturition, fever), acute pyelonephritis (high grade fever with chills and costovertebral tenderness), anaemia (haemoglobin of less than $10 \mathrm{~g} \%$ ), gestational hypertension (BP of 140/90 $\mathrm{mm}$ of $\mathrm{Hg}$ or more with the absence of proteinuria), preeclampsia (BP of 140/90 mm of $\mathrm{Hg}$ or more with significant proteinuria), preterm labour (uterine contractions of 4 in 20 minutes, cervical dilatation of more than $1 \mathrm{~cm}$ and cervical effacement of more than $80 \%$ before 37 weeks of gestation), PPROM (clear fluid coming out of cervical os on speculum examination before onset of labour and before 37 weeks),
PROM ( fluid coming out of cervical os on speculum examination before onset of labour due to rupture of membranes), puerperal pyrexia (oral temperature of $\geq 38^{\circ} \mathrm{C}$ after 24 hours and up to 1 week postpartum ) and foetal morbidity in the form of LBW (birth weight of $<2500$ grams ), IUGR (foetal weight below $10^{\text {th }}$ percentile for its gestational age), NICU admission (due to low Apgar /prematurity/LBW/neonatal septicaemia/meconium aspiration syndrome) were noted during the follow up of these patients.

\section{Statistical analysis}

All the statistical analysis was performed by using Microsoft excel and SPSS version 16. All quantitative variables were expressed as Mean \pm S.D and qualitative variables were expressed as frequencies and percentages. Chi-square test was used for examining the categorical data. For all statistical analysis, a P-value of less than 0.05 was considered as statistically significant.

\section{RESULTS}

A total 165 antenatal women were included in the study. In the ASB negative group, one woman had missed abortion at 14 weeks and 3 women were lost to follow up. They were replaced by another 4 women who immediately followed them in the antenatal register.

95 pregnant women were screened at or less than 20 weeks and they were grouped as early detected group (ED). In this group 11 women were culture positive with a prevalence of $11.57 \%$. 70 women were screened at 28 37 weeks of pregnancy and were considered as the late detected group (LD) out of which 12 women showed significant growth giving a prevalence of $17.14 \%$. Overall, 23 pregnant women had significant bacteriuria giving a prevalence rate of $13.93 \% .83 \%$ of the women screened belonged to the younger age of 18-24 years and $62 \%$ were primigravidae. $56 \%$ of the pregnant women belonged to lower socioeconomic class (Table 1).

The mean age of the pregnant women in the ASB negative group, ED group and LD group is 21.47 \pm 3.04 , $22.00 \pm 3.19$ and $23.08 \pm 3.45$ respectively (Table 2). 2 $(18 \%)$ women in ED group and $3(25 \%)$ women in LD group had anaemia as against $12(8 \%)$ women in ASB negative group (Table 3). 2 (16\%) women in LD group had symptomatic UTI when compared to $1(9 \%)$ woman in ED group. The incidence of UTI is $1.4 \%$ in ASB negative group which is statistically significant. The present study showed that $2(16.66 \%)$ pregnant women in LD group and $1(9.09 \%)$ in the ED group had PIH as against $4(16.66 \%)$ women in the ASB negative group. No woman in the ED group and $1(8.33 \%)$ woman in LD group had PROM as against $3(8.33 \%)$ women in the ASB negative group (Table 3). $1(9.09 \%)$ woman in the ED group and $3(25 \%)$ women in the LD group had preterm labour as against $6(2.5 \%)$ women in the ASB negative group which was statistically significant. 4 
(33\%) babies had low birth weight in LD group when compared to $1(9 \%)$ in the ED group (Table 4). Only 4 (2.8\%) babies in the ASB negative group had low birth weight which was highly significant. $3(2.11 \%)$ babies in the ASB negative group and $2(16.66 \%)$ babies in the LD group had IUGR whereas none of the babies in the ED group had IUGR which was significant.

Table 1: Distribution of pregnant women according to age, parity and socioeconomic status.

\begin{tabular}{|c|c|c|c|c|c|c|}
\hline Factor & $\begin{array}{l}\text { Early detected } \\
\text { group }(n=11)\end{array}$ & $\begin{array}{l}\text { Late detected } \\
\text { group }(n=12)\end{array}$ & $\begin{array}{l}\text { Total no. of } \\
\text { ASB positive } \\
\text { women }\end{array}$ & $\begin{array}{l}\text { Total no. of } \\
\text { ASB negative } \\
\text { women }\end{array}$ & $\begin{array}{c}\text { Prevalence } \\
\%\end{array}$ & $\begin{array}{l}\text { Chi } \\
\text { square, } P \\
\text { value }\end{array}$ \\
\hline \multicolumn{7}{|l|}{ Age } \\
\hline $18-24$ & 9 & 8 & 17 & 120 & 12.40 & \multirow{2}{*}{$\begin{array}{l}1.58 \\
0.20\end{array}$} \\
\hline $25-34$ & 2 & 4 & 6 & 22 & 21.42 & \\
\hline \multicolumn{7}{|l|}{ Parity } \\
\hline Gravida 1 & 6 & 4 & 10 & 93 & 9.70 & \multirow{6}{*}{$\begin{array}{l}16.2 \\
0.006 *\end{array}$} \\
\hline Gravida 2 & 3 & 6 & 9 & 33 & 21.42 & \\
\hline Gravida 3 & 2 & nil & 2 & 14 & 12.50 & \\
\hline Gravida 4 & nil & nil & nil & 2 & 0 & \\
\hline Gravida 5 & nil & 1 & 1 & nil & 100 & \\
\hline Gravida 6 & nil & 1 & 1 & nil & 100 & \\
\hline \multicolumn{7}{|c|}{ Socio economic status } \\
\hline Lower class & 6 & 8 & 14 & 79 & 15.05 & \multirow{4}{*}{$\begin{array}{l}0.42 \\
0.93\end{array}$} \\
\hline Lower middle class & 5 & 3 & 8 & 53 & 13.11 & \\
\hline Middle class & nil & 1 & 1 & 9 & 10.00 & \\
\hline Upper middle class & nil & nil & nil & 1 & 100 & \\
\hline Total & 11 & 12 & 23 & 142 & - & \\
\hline
\end{tabular}

Table 2: Comparison of mean of different obstetric variables between three groups.

\begin{tabular}{|c|c|c|c|c|c|}
\hline Parameter & Group & $\begin{array}{l}\text { No. of women } \\
\text { (n) }\end{array}$ & Mean & $\begin{array}{l}\text { Standard } \\
\text { deviation }\end{array}$ & P value \\
\hline \multirow{3}{*}{ Maternal age in years } & ASB negative & 142 & 21.47 & 3.045 & \multirow{3}{*}{0.205} \\
\hline & ED & 11 & 22.00 & 3.194 & \\
\hline & LD & 12 & 23.08 & 3.450 & \\
\hline \multirow{3}{*}{$\begin{array}{l}\text { Gestational age in weeks } \\
\text { at sampling }\end{array}$} & ASB negative & 142 & 20.63 & 8.601 & \multirow{3}{*}{$0.000^{*}$} \\
\hline & ED & 11 & 13.82 & 4.355 & \\
\hline & LD & 12 & 30.25 & 1.913 & \\
\hline \multirow{3}{*}{$\begin{array}{l}\text { Gestational age in weeks } \\
\text { at delivery }\end{array}$} & ASB negative & 142 & 38.20 & 1.518 & \multirow{3}{*}{$0.004 *$} \\
\hline & ED & 11 & 37.55 & 1.036 & \\
\hline & LD & 12 & 36.83 & 0.835 & \\
\hline \multirow{3}{*}{$\begin{array}{l}\text { Birth weight in } \\
\text { kilograms }\end{array}$} & ASB negative & 142 & 2.96 & 0.217 & \multirow{3}{*}{$0.000 *$} \\
\hline & ED & 11 & 2.78 & 0.288 & \\
\hline & LD & 12 & 2.55 & 0.260 & \\
\hline
\end{tabular}

*significant

$1(9.09 \%)$ baby from ED group, $3(25 \%)$ babies from LD group had NICU admissions compared to 6 (4.22\%) babies from ASB negative group. This difference was statistically significant (Table 4).

Escherichia coli $(52 \%)$ and Staphylococcus aureus (26\%) were the predominant organisms isolated (Table 5). 2 women in the ED group and 1 woman in the LD group needed another course of antibiotics for the clearance of bacteriuria.
$78 \%$ of the uropathogens isolated were sensitive to Nitrofurantoin and almost $95 \%$ were sensitive to Imipenem (Table 6).

\section{DISCUSSION}

The prevalence rate of ASB in the present study is $13.93 \%$ which is comparable with the study of Verma A et al $(12.27 \%) .^{20} \mathrm{~A}$ lower prevalence rate of $8.4 \%$ and $8.25 \%$ was obtained in a study by Lavanya SV et al and Radha $\mathrm{S}$ et al respectively. ${ }^{10,21}$ This may be because most 
of the patients in our study were rural women with lower level of education and socioeconomic status. Jain $\mathrm{V}$ et al and Paari $\mathrm{P}$ et al observed a higher prevalence of $16.9 \%$ and $21.1 \%$ respectively. ${ }^{12,11}$ This can be explained by the variation in the population studied, their hygienic practices and socioeconomic status. Elzayat MA et al, in their study observed that ASB was significantly higher in the pregnant women who had sexual intercourse more than twice in a week and in the women who reported washing their genitals from back to front after defaecation. $^{22}$

Table 3: Comparison of maternal outcome in early detected (ED), late detected (LD) and ASB Negative women.

\begin{tabular}{|c|c|c|c|c|c|}
\hline $\begin{array}{l}\text { Maternal } \\
\text { complication }\end{array}$ & Category & Percentage & Odds ratio & $95 \%$ confidence interval & P value \\
\hline \multirow{3}{*}{ Anaemia } & ED versus ASN & 18.18 versus 8.45 & 2.40 & $0.46-12.43$ & 0.29 \\
\hline & LD versus ASN & 25.0 versus 8.45 & 3.61 & $0.86-15.15$ & 0.07 \\
\hline & LD versus ED & 25.0 versus 18.18 & 1.50 & $0.20-11.23$ & 0.69 \\
\hline \multirow{3}{*}{ Symptomatic UTI } & ED versus ASN & 9.09 versus 1.40 & 7.00 & $0.58-83.98$ & 0.12 \\
\hline & LD versus ASN & 16.66 versus 1.40 & 14.0 & $1.78-110.09$ & $0.01 *$ \\
\hline & LD versus ED & 16.66 versus 9.09 & 2.00 & $1.15-25.75$ & 0.59 \\
\hline \multirow{3}{*}{$\begin{array}{l}\text { Gestational HTN/ } \\
\text { preeclampsia }\end{array}$} & ED versus ASN & 9.09 versus 2.81 & 3.45 & $0.35-33.84$ & 0.28 \\
\hline & LD versus ASN & 16.66 versus 2.81 & 6.90 & $1.12-42.36$ & $0.03 *$ \\
\hline & LD versus ED & 16.66 versus 9.09 & 2.00 & $0.15-25.75$ & 0.59 \\
\hline \multirow{3}{*}{ PPROM } & ED versus ASN & 9.09 versus 1.40 & 7.00 & $0.58-83.98$ & 0.12 \\
\hline & LD versus ASN & 8.33 versus 1.40 & 6.36 & $0.53-75.81$ & 0.14 \\
\hline & LD versus ED & 8.33 versus 0 & 0.90 & $0.05-16.54$ & 0.94 \\
\hline \multirow{3}{*}{ PTL } & ED versus ASN & $9.09 \mathrm{vs} 4.22$ & 2.26 & $0.24-20.70$ & 0.46 \\
\hline & LD versus ASN & 25.0 versus 4.22 & 7.55 & $1.61-35.29$ & $0.01 *$ \\
\hline & LD versus ED & 25.0 versus 9.09 & 3.33 & $0.29-38.08$ & 0.53 \\
\hline \multirow{3}{*}{ PROM } & ED versus ASN & 0 versus 2.11 & 1.73 & $0.08-35.63$ & 0.72 \\
\hline & LD versus ASN & 8.33 vs 2.11 & 4.21 & $0.40-43.94$ & 0.22 \\
\hline & LD versus ED & 8.33 versus 0 & 3.00 & $0.11-81.61$ & 0.51 \\
\hline \multirow{3}{*}{ Puerperal pyrexia } & ED versus ASN & 0 versus 1.40 & 2.44 & $0.11-53.98$ & 0.57 \\
\hline & LD versus ASN & 8.33 versus 1.4 & 6.36 & $0.53-75.81$ & 0.14 \\
\hline & LD versus ED & 8.33 versus 0 & 3.00 & $0.11-81.61$ & 0.51 \\
\hline APN & - & - & - & - & - \\
\hline
\end{tabular}

*significant

Table 4: Comparison of foetal outcome in Early detected (ED), Late Detected (LD) and ASB negative women.

\begin{tabular}{|c|c|c|c|c|c|}
\hline Foetal morbidity & Category & Percentage & Odds ratio & $\begin{array}{l}95 \% \text { confidence } \\
\text { interval }\end{array}$ & $P$ value \\
\hline \multirow{3}{*}{ LBW } & ED versus ASN & 9.09 versus 2.81 & 3.45 & $0.35-33.84$ & 0.28 \\
\hline & LD versus ASN & 33.33 versus 2.8 & 17.25 & $3.63-81.96$ & $0.0003^{*}$ \\
\hline & LD versus ED & 33.33 versus 9.09 & 5.00 & $0.46-54.04$ & 0.18 \\
\hline \multirow{3}{*}{ IUGR } & ED versus ASN & 0 versus 2.11 & 1.73 & $0.08-35.63$ & 0.72 \\
\hline & LD versus ASN & 16.66 versus 2.11 & 9.26 & $1.38-62.00$ & $0.02 *$ \\
\hline & LD versus ED & 16.6 versus 0 & 5.47 & $0.23-127.7$ & 0.29 \\
\hline \multirow{3}{*}{ NICU admission } & ED versus ASN & 9.09 versus 4.22 & 2.26 & $0.24-20.70$ & 0.46 \\
\hline & LD versus ASN & 25.0 versus 4.22 & 7.55 & $1.61-35.29$ & $0.01 *$ \\
\hline & LD versus ED & 25.0 versus 9.09 & 5.00 & $0.46-54.04$ & 0.18 \\
\hline
\end{tabular}

The occurrence of anemia was high in all the groups. So not statistically significant. This could be due to several other etiological factors for anemia which were not considered in our study. The women of LD group had 14 times greater Odds of developing UTI in pregnancy when compared to ED group in the present study. Not only that, previous history of UTI was shown as a definite risk factor for ASB by Tahir $\mathrm{S}$ et $a .^{23}$ The present study shows that women in LD group had 6.9 times greater Odds of developing gestational HTN or Preeclampsia similar to the findings of Radha $\mathrm{S}$ et al and $\mathrm{Yu}$ FN et al. $^{21,24}$ However, no case of Gestational HTN or 
Preeclampsia was noted by Nkwabong E et al in their study. ${ }^{25}$ No case of acute pyelonephritis occurred in any of the three groups in the present study. Contrary to the study by Jain $\mathrm{V}$ et al, there was no significant increase in occurrence of PPROM in the present study.

Table 5: Bacteria isolated in culture positive women.

\begin{tabular}{|lll|}
\hline Bacterium isolated & $\begin{array}{l}\text { No. of cases } \\
(\mathbf{n = 2 3})\end{array}$ & $\begin{array}{l}\text { Percentage } \\
\text { Escherichia coli }\end{array}$ \\
\hline Staphylococcus aureus & 6 & 52.17 \\
\hline Klebsiella pneumoniae & 3 & 26.08 \\
\hline Enterococcus sp. & 2 & 13.04 \\
\hline Total & 23 & 08.69 \\
\hline
\end{tabular}

Table 6: Antibiotic sensitivity pattern of various uropathogens.

\begin{tabular}{|ll|}
\hline Antibiotic & $\%$ sensitivity \\
\hline Imipenem & 95.00 \\
\hline Nitrofurantoin & 78.26 \\
\hline Cefotaxim & 52.17 \\
\hline Amikacin & 30.43 \\
\hline Amoxicillin with clavulanic acid & 30.43 \\
\hline Cefoxitin & 21.73 \\
\hline Ceftazidime & 13.04 \\
\hline Cefuroxime & 13.04 \\
\hline Ceftriaxone & 8.6 \\
\hline Ampicillin & 8.6 \\
\hline Amoxicillin & 4.3 \\
\hline
\end{tabular}

The association of ASB with preterm labour and LBW is still controversial. In the present study the women of LD group had 7.55 times greater Odds of having PTL when compared to ASB negative group which was highly significant. The ED group had 2.26 times greater Odds of delivering preterm when compared to the ASB negative group. This is in consonance with the study of Jain $\mathrm{V}$ et al and Radha SK et al. Izuchukwu KE et al and Yu FN et al observed no significant increase in the risk of preterm birth in their study. ${ }^{26}$ They observed that this could be due to early initiation of antibiotics in culture positive women. In the present study in spite of treatment of ASB, the bacteriuric women developed PTL and LBW which is similar to the observations of Jain $\mathrm{V}$ et al. This could be due to several confounding factors for PTL in the present study such as teenage pregnancy, low pre-pregnancy $\mathrm{BMI}$, anemia, poor nutrition in the pregnant women of lower socioeconomic group, passive smoking which were not ruled out. So, the greater Odds of developing PTL and LBW in the LD group in the present study cannot be attributed to ASB alone.

However, a retrospective population based study by Sheiner E et al concluded that ASB is an independent risk factor for preterm delivery. ${ }^{27}$ In a case control study by Molina JP et al, ASB as a risk factor of spontaneous preterm birth was investigated and they reported that
ASB had a moderate trend to be associated with preterm birth and infectious processes are only a part of its multiple etiologies. ${ }^{28}$ No significant increase in the risk of puerperal pyrexia was noted in any of the three groups.

The women of LD group had 17.25 times greater Odds of delivering a LBW baby when compared to ASB negative women and 5 times greater Odds of delivering a LBW baby when compared to ED group which is highly significant. This is in accordance with the study of Nkwabong E et al.

The women of LD group had 9 times greater Odds of having IUGR babies as compared to ASB negative women which was statistically significant. This finding is comparable with that of Jain V et al. This may be due the adverse effects of ASB which would have already established even before treatment is initiated. So, the LD group had significantly greater Odds of delivering preterm and LBW babies. However, a much larger randomized multicentric study is needed to establish this association. The babies of LD group had 7.55 times greater Odds of admission to NICU when compared to ASB negative group and 5 times greater Odd's when compared to ED group respectively which is statistically significant. These findings are comparable to the findings of Yu FN et al.

Escherichia coli was the predominant organism isolated. This is comparable to the findings of Nkwabong $\mathrm{E}$ et al and Taher et al. $78 \%$ of uropathogens were sensitive to Nitrofurantoin which is comparable to the findings of Radha $\mathrm{S}$ et al. All the microbes isolated were resistant to Amoxicillin and Ampicillin except Enterococcus species. The antibiotic sensitivity varies from place to place. Local resistence rates should be considered while prescribing treatment. $13 \%$ of culture positive women showed persistence of bacteriuria after a course of antibiotics. Recurrence with the same organism or failure to eliminate is indicative of renal parenchymal infection or structural abnormality. ${ }^{29}$ These women were advised follow up culture and urologic examination after delivery.

The prevalence of ASB is very high in the present study. The morbidity related to ASB when treated early in pregnancy is minimized. Wadland et al in their study observed that universal urine screening for pregnant women is cost effective if the prevalence of ASB is greater than $2 \%$ and the cost of the screening tests was less than 26 US\$..$^{30}$

The expenditure incurred in the treatment of the complications of ASB is enormous when compared to the cost of urine culture and sensitivity. So, screening for ASB with urine culture and sensitivity early in pregnancy should be routinely done in all pregnant women ideally at 12-16 weeks of pregnancy or in their first visit. Women with a history of UTI in the previous pregnancy should definitely be screened for ASB. Apart from that, simple measures like imparting health education to the antenatal 
women about personal hygiene, cleaning of genitalia from back to front after defaecation, reducing the frequency of sexual intercourse during pregnancy, emptying the bladder after sexual intercourse help to reduce the prevalence of ASB and the morbidity associated with it.

\section{CONCLUSION}

Screening for asymptomatic bacteriuria early in pregnancy at less than 20 weeks is more effective in reducing the adverse maternofoetal outcome.

\section{ACKNOWLEDGMENTS}

Authors thank the Professor and head of the department of Obstetrics and Gynaecology Dr. Jayalakshmi M., Dr. T. N. Rao, Professor of Obstetrics and Gynaecology and all the participants of this study for their cooperation.

\section{Funding: No funding sources}

Conflict of interest: None declared

Ethical approval: The study was approved by the Institutional Ethics Committee

\section{REFERENCES}

1. Delzell JE, Lefevre ML Urinary tract infections during pregnancy. Am Fam Physician 2000;61(3):713-21.

2. Kass EH. Bacteriuria in pregnancy and pyelonephritis of pregnancy. Arch Interna Med. 1960;105:194-8.

3. Uncu Y, Uncu G, Esmer A, Bilgel N. Should asymptomatic bacteriuria be screened in pregnancy? Clin Exp Obstet Gynecol. 2002;29:281-5.

4. Farkash E, Weintraub AY, Sergienko R, Wiznitzer A, Zlotnik A, Sheiner E. Acute antepartum pyelonephritis in pregnancy: a critical analysis of risk factors and outcomes. EJOG. 2012;162(1):24-7.

5. Smaill F, Vazquez JC. Antibiotics for asymptomatic bacteriuria in pregnancy. Cochrane Database Syst Rev. 2007;(2):CD000490.

6. Connolly A, Thorp JM. Urinary tract infections in pregnancy. Urol Clin North Am. 1999;26:779-87.

7. The U.S. preventive services task force screening for asymptomatic bacteriuria, haematuria and proteinuria. APP. 1990;42:389-95.

8. Schnarr J, Smaill F. Asymptomatic bacteriuria and symptomatic urinary tract infections in pregnancy. Euro J Clin Invest. 2008;38:50-7.

9. Teppa RJ, Roberts JM. The uriscreen test to detect significant asymptomatic bacteriuria during pregnancy. J Soc Gynecol Investig 2005;12(1):50-3.

10. Lavanya SV, Jogalaxmi D. Asymptomatic bacteriuria in antenatal women. Ind J Med Microbiol. 2002;20(2);105-6.

11. Paari P, Sindhuja TP, Dhinakaran S, Paul CMP. A cross sectional study on asymptomatic bacteriuria among antenatal women attending an urban tertiary health care center in southern India. Int J Reprod Contracept Obstet Gynecol. 2017;6:4522-5.

12. Jain V, Das V, Agarwal A, Pandey A. Asymptomatic bacteriuria and obstetric outcome following treatment in early versus late pregnancy in north Indian women. Indian J Med Res. 2013;137(4):7538.

13. Babu GRJ, Srikrishna R, Ramesh ST. Asymptomatic bacteriuria in pregnancy Int $\mathrm{J}$ Biol Med Res. 2011;2(3):740-2.

14. Gratacos E, Torres PJ, Vila J, Alonso PL, Cararch V. Screening and treatment of asymptomatic bacteriuria of pregnancy to prevent pyelonephritis. J Infect dis 1994;169;1390-92.

15. Adam T, Lim SS, Mehta S, Butta ZA, Fogstad H, Mathai $M$, et al. Achieving the millennium development goals for health-cost effectiveness analysis of strategies for maternal and neonatal health in developing countries. BMJ. 2005;331:110712.

16. Kasraein M, Asadi N, Gaffarpasand F. Prevalence of asymptomatic bacteriuria among pregnant women in Shiraz, Iran. Saudi Med J. 2009;30(7):917-20.

17. Tuqrul S, Oral O, Kumru P, Kose D, Alkan A, Yildirim G. Evaluation and importance of asymptomatic bacteriuria in pregnancy. Clin Exp Obstet Gynecol. 2005;32(4):237-40.

18. Guntoory I, Tamaraba NR, Rayapu SB. Prevalence of asymptomatic bacteriuria in pregnancy at a teaching hospital. J Evolution Med Dent Sci. 2016;5(57):3951-5.

19. Singh J, Sharma S, Nagesh S. Socioeconomic status scales updated for 2017. Int J Res Med Sci. 2017;5(7):3264-7.

20. Verma A, Baheti S, Sharma M. Asymptomatic bacteriuria in pregnancy and its relation to perinatal outcome. Int J Reprod Contracept Obstet Gynecol. 2016;5:4390-6.

21. Radha S, Nambisan B, Prabhakaran NK, Jamal S. Prevalence and outcome of Asymptomatic bacteriuria in early pregnancy. Int $\mathbf{J}$ Reprod Contracept Obstet Gynecol. 2017;6:223-7.

22. Elzayat MA, Barnett-Vanes A, Dabour MFE, Cheng F. Prevalence of undiagnosed asymptomatic bacteriuria and associated risk factors during pregnancy: a cross sectional study at two tertiary centres in Cairo, Egypt. BMJ Open. 2017;7:e013198.

23. Tahir S, Tayyab M, Rasul S, Jabeen S, Gul A. PJMHS. 2015;9(4):1399-402.

24. Yu FN, Tung C, Fong S, Leung H, Cheung $\mathrm{H}$. Obstetric outcome for pregnant women with Asymptomatic bacteriuria in Hong Kong. HKJGOM 2016;16(1).

25. Nkwabong E, Moustapha E, Fomulu NJ. Outcome of pregnancy complicated by asymptomatic bacteriuria. Gynecol Obstet (Sunnyvale). 2014;4(259):21610932.

26. Izuchukwu KE, Oranu ED, Bassey G, Orazulike NC. Maternofetal outcome of asymptomatic bacteriuria 
among pregnant women in a Nigerian teaching hospital. Pan Afr Med J. 2017;27:69.

27. Sheiner E, Mazor DE, Levy A. Asymptomatic bacteriuria during pregnancy. J Maternfetal Neonatal Med. 2009;22:423-7.

28. Molina JP, Meza JG, Reyes JC, Baron GP, Hernandez JF. Preterm delivery and asymptomatic bacteriuria. Ginecol Obstet Mex. 2008;76(8):454-60.

29. Patterson TF, Andriole VT. Detection, significance and therapy of bacteriuria in pregnancy. Update in the managed health care era. Infect Dis Clin North Am. 1997;11(3):593-608.
30. Wadland WC, Plante DA. Screening for asymptomatic bacteriuria in pregnancy: a decision and cost analysis. J Fam Pract. 1989;29(4):372-76.

Cite this article as: Guntoory I, Penmetsa P, Rayapu SB, Nambaru LR. Maternofetal outcome in early versus late detected Asymptomatic bacteriuria of pregnancy. Int J Reprod Contracept Obstet Gynecol 2018;7:80-7. 